\title{
The controversial relationship between neuroscience and moral responsibility in psychopaths
}

\author{
José Eduardo Muñoz-Negro ${ }^{1,8^{*}}$ (D), José Pablo Martínez Barbero², Felicity Smith ${ }^{3,4}$, Brooke Leonard ${ }^{5}$, \\ Jaime Padilla Martínez ${ }^{6}$ and Inmaculada Ibáñez-Casas ${ }^{7}$
}

\begin{abstract}
Background: From fields such as neuroethics and legal medicine it is increasingly common to raise the issue on whether it is necessary to rethink questions such as moral and criminal responsibility in individuals fulfilling Hare's criteria for psychopathy. The Hare's Psychopathy Checklist Revised is currently the diagnostic gold standard for psychopathy and defines a type of personality characterized by interpersonal, affective, and behavioral symptoms. Moral and criminal responsibility in these individuals is now being reconsidered due to new data provided by neuroscience. However, the translation from these neuroscientific findings into terms of moral responsibility is neither direct nor evident. The aim of this review is to assemble the available neuroscientific evidence and to clarify the moral consequences of these findings.
\end{abstract}

Main text: A genetic base for psychopathy exists as well as brain functionality or even structural variations. However, these structural changes are not robust and consistent across the different studies. Moreover, this body of evidence uses different methodologies and, for this reason, it is hardly comparable. Findings from the field of neuropsychology such as the emotional alterations, empathy impairment or emotional theory of mind (ToM) deviance are equivocal, controversial, and a focus of debate. These can be well understood as correlates of the particular psychopaths' moral functioning more than as a deterministic causality for their conduct. In addition, a biological and neuropsychological model of moral responsibility open to scientific analysis does not exist. Ultimately, moral responsibility has a biological and neuropsychological basis, but it cannot be fully explained by these constructs.

Conclusion: This review assesses new findings in the study of moral and criminal responsibility in psychopaths, and the different interpretations about them. It concludes that, in the absence of an experimental model of moral responsibility, current data, though controversial, are not definitive arguments that can reduce or to eliminate moral, and subsequently, criminal responsibility.

Keywords: Psychopathy, Hare psychopathy checklist revised, Moral responsibility, Neuroscience, Neuroethics

\section{Background}

In the past several years, neuroscience has been contributing data to allow for the development of new constructs such as the moral (Hauser, 2008) and the ethical mind (Gazzaniga, 2006). In this context, the question about the responsibility of psychopaths is not only of interest for legal repercussions for criminal behavior, but

\footnotetext{
* Correspondence: jemunoznegro@gmail.com

'Mental Health Clinical Management Unit Granada South, Andalusian Health Service, Granada, Spain

${ }^{8}$ Departament of Psychiatry, Faculty of Medicine, University of Granada, Avda. de la Investigación 11, 18016 Granada, Spain

Full list of author information is available at the end of the article
}

it also brings about important questions about the nature of moral responsibility and its cognitive and emotional components that are deeply rooted in the brain.

At present, the personalities characterized by antisocial behavior are present in three categories: Antisocial Personality Disorder (American Psychiatric Association, 2013), Dissocial Personality Disorder (World Health Organization, 1992), and Hare's psychopathy Checklist Revised (Hare, 2003). The latter was clinically defined by Cleckley (Cleckley, 1994) and Hare defined the criteria in his Psychopathy Checklist (Hare, 2003). These criteria are currently used as an operational definition of 
psychopathy. This construct has shown its usefulness in Legal Medicine (Torrubia-Beltri \& Cuquerella-Fuentes, 2008). It is estimated that $15-25 \%$ of inmates are psychopaths according to this definition and around 65\% meet the criteria for Antisocial Personality Disorder. The prevalence of psychopathy in the general population is 1\% (Torrubia-Beltri \& Cuquerella-Fuentes, 2008). Psychopathy is not the same as Child Conduct Disorder nor Antisocial Personality Disorder; these both share antisocial behavior, but do not share the rest of the criteria. A third of individuals diagnosed with Antisocial Personality Disorder will meet the criteria for psychopathy (Hart \& Hare, 1966).

The Hare Psychopathy Checklist Revised (Hare, 2003) defines a type of personality characterized by interpersonal, affective, and behavioral symptoms. Currently, it is considered the gold standard for psychopathy diagnosis, offering good reliability and validity (Alcázar-Córcoles et al., 2008; Hare et al., 1990) for clinical, forensic and research purposes. It is composed of a semi-structured interview, which gathers information on the case history with 20 Likert-scale items The Hare Psychology Checklist Revised evaluates a psychopathological construct based on four underlying dimensions: interpersonal, affective, lifestyle, and antisocial. For clinical and research purposes, a score of 30 is considered indicative of psychopathy (Neumann et al., 2015). The 20 items evaluate psychopathy traits and behaviors such as superficial charm, grandiose sense of self-worth, need for stimulation, pathological lying, manipulation, lack of remorse, shallow affect, lack of empathy, parasitic lifestyle, poor behavioural control, promiscuous sexual behaviour, early behavioural problems, lack of realistic problems, impulsivity, irresponsibility, failure to accept responsibility, many short-term relationships, juvenile delinquence, revocation of conditional release and criminal versatility (Hare et al., 1990).

Some authors have proposed a classification into primary and secondary psychopaths (Coid et al., 2012). The former can be exceptionally intelligent and highly capable of carrying out their plans, while the latter have greater cognitive deficits, greater impulsivity, more anger, poor planning capabilities, presenting greater digression from social norms.

In the fields of neuroethics and forensic psychiatry, there is an ongoing discussion about the current findings of biological and neuropsychological correlates of psychopathy. And on whether it is necessary to consider that psychopaths suffer from a disorder, in this case "crazy morals" (Holmes, 1991), that mitigates or excuses their moral and legal responsibility.

Our objective is to determine if the growing neuroscientific body of evidence about the underlying cognitive processes of the moral behavior of psychopaths actually changes their morality and, by consequence, legal conduct or if it is simply due to a conflict of interpretation between neuroscience and neuroethics.

\section{Main text \\ The biological basis and neuroscience of psychopathy}

Psychopathy is a defined disorder of emotional dysfunction and antisocial behavior (Frick et al., 2003; Harpur et al., 1988). Emotional dysfunction, allows for a diminished sense of guilt and a lack of empathy and connection with others. In children, this feature of emotional insensitivity is associated with antisocial conduct (Halty et al., 2011) and in turn, the antisocial component reflects a predisposition to antisocial acts from an early age. This pattern emerges before the age of ten and persists into adulthood (Harpur et al., 1988; Lynam et al., 2007).

In relation to the possible biological basis of psychopathy, two fundamental facts stand out: a) the existence of a genuine genetic basis (Bloningen et al., 2005; Viding et al., 2005) and b) the finding of functional and structural alterations in diverse brain regions such as the biological correlates of emotional alterations (orbitofrontal cortex, amigdala-hipocampus, insular cortex, anterior cingulate cortex), of antisocial behavior (superior temporal gyrus, dorsolateral prefrontal cortex, orbitofrontal cortex, and anterior cingulate cortex) and of the pathological tendency to lie exhibited by these patients (orbitofrontal cortex, anterior cingulate cortex, ventrolateral prefrontal cortex) (Yang \& Raine, 2008). Other authors emphasize the role of structures such as the ventromedial prefrontal cortex (Bechara et al., 1999) and the amygdala (Blair, 2006, 2007). Also, a few studies have found volumetric structural alterations in regions like the temporal lobe, the hippocampus (Raine et al., 2004), or the amygdala (Yang et al., 2009). These volumetric frontal alterations were found in some studies (Yang et al., 2005), but not in others (Dolan et al., 2002).

With regard to the genetic basis, some chromosomal abnormalities such as the XYY chromosome have been linked to psychopathy. Thus, the rate of this chromosomal abnormality in psychopaths is much higher $(1.8 \%)$ than in the general population (0.01\%) (Briken et al., 2006). In addition, Genome-wide association studies (GWAS) have shown a linkage between chromosome 13 at $11 \mathrm{cM}$ and antisocial behavior (Gizer et al., 2012). Regarding family studies, a study with 3500 pairs of twins has shown that the traits of cruelty and lack of emotiveness were inherited in $67 \%$ of the cases at 7 years of age (Viding et al., 2005). Different studies have established that the homozygotic carrier of a long allele of the serotonine transporter gene shows a diminished response of the amygdala before emotional expression, in relation to those that are homozygotes for the short allele (Hariri et al., 2002). It is possible that a variety of polymorphisms affects the function of the amygdala. However, they are 
not only influenced by genetic aspects, but also by socioeconomic status, being less probable in individuals of high social status (Silverthorn \& Frick, 1999). The social disadvantage motivates instrumental as well as reactive aggression. Also, it has also been suggested that psychopathy could be due to early sexual or physical abuse or some type of maltreatment (Rutter, 2005). These factors increase the risk of antisocial behavior, particularly aggression reactive to fear or frustration, as well as the increased emotional reaction to threatening stimuli. Nevertheless, psychopathy is characterized by low emotional reactivity to numerous stimuli.

\section{Emotional alterations}

Psychopaths show emotional coldness and a characteristic shortage of strong and intense emotions like fear. It has been shown that there is a weakened reflex of shock/fright and little emotional response towards emotionally unpleasant images as demonstrated through diminished skin conductance (Levenston et al., 2000; Patrick et al., 1994). Additionally, they seem not to learn about the consequences of their actions. This has been explained as a result of having impairments or deficits in aversive conditioning (Blair, 2008), which could be associated with difficulty to correct their behaviour through punishment. In this line, neuroimaging studies have shown activation deficits in brain structures involved in this kind of learning such as the orbitofrontal cortex, the anterior cingulate cortex, the amygdala, and the insula. The orbitofrontal cortex has an important role in the evaluation of negatively conditioned stimuli; the insula, in the evaluation of painful stimuli; and the anterior cingulate cortex, in emotional response (Yang \& Raine, 2008). Regarding brain structures, the amygdala and the ventromedial nucleus of the prefrontal lobe are two regions that are crucial in explaining the neuropsychology of psychopathy (Bechara et al., 1999; Blair, 2007, 2008). Both these areas allow for the integration of emotional and rational information into the decision-making process.

The amygdala is a brain structure that is crucial for stimulus-reinforcement learning (Davis \& Whalen, 2001; Everitt et al., 2006). This learning allows for specific representations of conditional stimuli from the temporal cortex to be connected to the emotional responses of the amygdala and other structures. In humans and other primates, fear and potential sadness serve as negative reinforcers, and the associated stimuli to these reinforcers need to be avoided. The amygdala allows individuals to learn the good and the bad of objects and actions (Blair, 2008). Certain stimuli are emotionally marked and then labelled as "good" or "bad" in both social and non-social settings. The amygdala also sends signals to the ventromedial prefrontal cortex, which is implicated in the representation of reinforcement of different objects and actions and allows us to learn from the experience and anticipate expectations. This information is key for decision-making and is utilized by other structures, like the anterior cingulate cortex. This intervenes when we need to make a decision when confronted with a moral conflict, where there is a dissonance between the purely rational and the emotional (R. Blair, 2008).

Psychopath behaviour has been theorized to be the result of an inability to integrate the emotional and rational information into executive decisions. The role of the emotions in the adequate decision-making process has been developed after the work of Antonio Damasio. His hypothesis of the somatic marker (Damasio, 1996) has shown how emotions are key in limiting the field of possible alternatives that are evaluated in rational deliberation; we learn from our own positive and negative experiences, emotionally "marking" the representations that are tied to specific options. We so anticipate what can happen if we choose one thing or another. His hypothesis manifests that decision making is a process where cognitive and emotional processes converge. This information gives us data to plan our future behavior, making decisions that are constantly reevaluated through experience. This executive capacity requires the integrity of the ventromedial nucleus of the prefrontal lobe (Damasio, 2008). A controversy exists over the function of this indicator in psychopaths. There are studies that propose that it is altered (Blair et al., 2001) and others that suggest the opposite (Blair and Cipolotti, 2000; Schmitt et al., 1999).

Finally, mirror neurons, a type of neuron that is fundamental to feelings of empathy which is located in the frontal and the insular regions, can also suffer functional alterations in psychopaths (Alcázar-Córcoles et al., 2008).

\section{Antisocial behaviour}

Psychopaths show poor impulse control and aggressive behaviour. A few studies have found functional alterations in specific areas of the brain related to antisocial behaviour. These studies showed lower activation in the anterior cingulate cortex and the temporal gyrus, in relation to control subjects, when the individual performs semantic processing tasks (Kiehl et al., 2017) as well as in other areas such as the amygdala, related to social cooperation (Rilling et al., 2007). They showed a clearly lower activation in the amygdala when they decided to desert or discontinue cooperating with someone with whom they were previously cooperating. Also, they showed diminished activation in the orbitofrontal cortex when they decided to collaborate with another person and little activation in the dorsolateral prefrontal cortex and anterior cingulate cortex when they decided to abandon the cooperation. The orbitofrontal cortex is used to calculate reward and punishment associated with 
stimuli. The dorsolateral prefrontal cortex and the anterior cingulate allow us to make decisions and execute them, while the superior temporal gyrus is a structure that is related to Theory of Mind (TOM) and moral reasoning (Yang \& Raine, 2008).

Some authors have found structural alterations in the hypothalamus and prefrontal cortex in "unsuccessful" psychopaths (habitually incarcerated) that they could not replicate in "successful" psychopaths (psychopaths that are integrated into society). Specifically, some found an exaggerated asymmetry in the hippocampus volume (right larger than left) (Raine et al., 2004) and a reduced volume of grey matter in the prefrontal cortex (Yang et al., 2005). These results point out that unsuccessful psychopaths can have a poorer capacity to learn aversive conditioning, emotional regulation and decision making.

\section{Neuropsychological alterations}

The set of biological traits and correlates mentioned above would result in alterations in the neuropsychological functioning. According to some authors, psychopaths appear to have a frontal lobe disorder that includes different types of alterations such as difficulty in concentrating, learning, abstract thinking and planning, as well as difficulty with certain impulse control (Navas-Collado \& Muñoz-García, 2004). These neuropsychological alterations find support in neuroimaging and electrophysiology studies using both EEGs and evoked potentials (Navas-Collado \& Muñoz-García, 2004). Specifically, psychopaths present with a poor cognitive performance in tasks such as the Stroop test, in which they show abnormal selective attention (Hiatt et al., 2004); reduced response-inhibition (Kiehl et al., 2000); poor stimulus-reinforcement learning (Flor et al., 2002); and poor aversive conditioning (Blair, 2006). Due to all this, they appear to have difficulty in learning from experiences that have negative consequences as much as with instrumental learning (Blair, 2003). Not all studies have confirmed these findings. For instance, one study found a prefrontal function similar to that of control subjects that would allow for good planning strategies amongst psychopaths (Raine et al., 1998).

There is currently an important controversy on whether psychopaths have a deficit in emotion recognition or not. Some studies show that psychopaths can react to stimuli that are not related to fear or sadness (Flor et al., 2002). However, a metaanalysis with 1376 participants concluded that the deficit in emotion recognition is global and goes beyond fear and sadness (Dawel et al., 2012). Some studies suggest that these difficulties in emotion recognition disappear when psychopaths are asked to identify emotions using the eye area only, and not the entire face (Dadds et al., 2006; Richell et al., 2003).
Another source of strong discrepancies is in the area of Theory of Mind (ToM) in psychopaths. One of the aforementioned studies was unable to find alterations in ToM in these individuals (Richell et al., 2003). Some other studies align with the idea of ToM in psychopaths being relatively intact and suggest that this can be an adaptation tool to their criminal lifestyle or an evolutionary adaptation (Dolan \& Fullam, 2004). It would be related with a special ability to recognize the emotional vulnerability of their potential victims. Psychopaths have been found to have a more accurate ability to detect hostility in others, as compared to controls. Psychopaths would also have a greater ability to recognize emotions in the face and eyes than individuals with antisocial disorder not fulfilling criteria for psychopathy (Dolan \& Fullam, 2004). Other authors distinguish between "cognitive" and "emotional" ToM (Shamay-Tsoory et al., 2010). In this study, correlations were found between the two dimensions of the Hare psychopathy construct and specific types of empathy. The dimension of psychopathy and characteristics of cruelty would correlate with the ability to detect neutral mental states, but not positive or negative, and the antisocial dimension would correlate with a deficit in interpreting mental states. According to this study, psychopaths would have intact cognitive, but not emotional, empathy. They would be able to manipulate the mind of others through this cognitive empathy but not to limit their aggressiveness through mental preparation based on emotional empathy. Other studies also emphasize that emotional empathy is altered in psychopaths in the same way it is altered in people with abnormalities in the orbitofrontal cortex (Shamay-Tsoory et al., 2010). In studies using moral dilemmas, some neuroimaging studies have also found a lower brain activation in areas related to ToM, empathy, and default mode network in subjects with psychopathy as compared to controls when they evaluated moral dilemmas (Reniers et al., 2012).

Psychopathy is also associated with limitations in reversal learning (Budhani, Richell, \& Blair, 2006). Reversal learning is a type of learning where the individual is trained to respond differentially to two stimuli associated with conditions of reward and punishment, and later these conditions are inverted. Psychopaths find it difficult to detect the positive or negative reinforcers associated with certain stimuli. They do not adequately detect that what was previously associated with a positive reinforcer is now associated with a negative one. Reversal learning depends essentially on the functional integrity of the ventromedial nucleus of the frontal lobe. This dysfunction creates problems with learning from personal, daily experiences and making decisions for the future. The subject would have trouble identifying that the behaviour they previously associated with a reward or 
success, now has come to be associated with the opposite and vice versa.

\section{Psychopathy and moral responsibility}

Currently, there are many authors who postulate a reduction in the moral responsibility of psychopaths, whilst maintaining at least a legal responsibility, although this is also reduced in some cases. The main arguments supporting this reduction in moral responsibility are the following: 1 . Moral blindness, understood as a lack of understanding of the moral nature and content of their actions; 2 . The inability to distinguish between social and moral transgressions; 3 . Difficulty in learning the consequences of their actions.

\section{Moral blindness}

This argument states that psychopaths are unable to recognise the wrongdoing of their actions due to their emotional deficits. Accordingly, they are unable to value moral reasoning, making moral deliberation either significantly lessened or impossible. This argument largely rests on the psychopaths' dysfunction in empathy and recognition of emotions. Modern neuroscience has made clear the link between reason and emotions (Alcázar-Córcoles et al., 2008); from this perspective it is difficult to consider emotions and rationality as two distinct faculties when it comes to discussions regarding moral responsibility.

Other authors emphasize the inability of psychopaths to understand the moral content of their transgressions (Finlay, 2011). It is argued that, due to their lack of empathy, they cannot feel the harm caused to others, nor do they respect them as people. Their actions lack moral content and thus, strictly speaking, are not to be considered moral actions (Levy, 2014). Insufficient empathy found in psychopaths could be crucial in comprehending their lack of deep moral understanding (Blair, 2008; Glannon, 1997). Empathy is as much a mode of figuring out what other people feel, as of vicariously feeling emotions. There are distinct "routes" to empathy: one form of empathizing is to recognise emotions through non-verbal communication, whereas another lies in the capacity to put oneself in another's shoes. What they have in common is that the person who empathizes is able to experience the very same emotion, as they have the ability to imagine the other person feeling that emotion. Other authors state that empathy is necessary for the development of an ethic based on universal Kantian concerns (Deigh, 1995). Their lack of empathy would make these individuals less receptive to certain ethical reasoning, which they appear to understand, but towards which they present no inclination. Following these authors, the deficits in empathy would significantly limit their ability to recognise ethical scenarios, as well as the motivation for ethical actions.
However, other authors criticize these assertions regarding the lack of empathy of psychopaths as unproven and speculative (Maibom, 2008), further highlighting that, in any case, empathy is not the only source of moral understanding. Additionally, they remark that no test indicates that psychopaths lack the ability necessary to understand the purpose of regulating conduct according to universal ethical maxims. On the basis of a rationalist interpretation, psychopaths do not lack the capability to understand what is bad. It is argued that they are even able to recognise that others could be harmed as a result of their actions (Elliott, 1992). Rather than a lack of empathy, they are said to have a deficiency, and therefore, they claim that it cannot be argued that they are completely devoid of moral responsibility (Maibom, 2008).

In a similar vein, these authors also depict the lack of psychopaths' moral responsibility as relating to their difficulty to realise "mental time travel" (Levy, 2014). This refers to a mental operation in which we connect our own memories with forecasts about the future in order to construct an autobiographical synthesis. This mental capacity depends upon the soundness of the cerebral circuits that automatically make up the network. Without this capacity, we could not recognise others as people with their own future projects. According to these authors, for psychopaths, there is no difference between killing a person and stepping on an insect, since they do not recognise people as the people that they are. These authors equate the moral responsibility of psychopaths with that of adolescents or children (Vierra, 2016). Nonetheless, this apparent dysfunction in psychopaths is not experimentally proven, nor is the claim that its affectation would be definitive in the determination of moral responsibility.

Ultimately, moral responsibility should not be reduced to its biological or neuropsychological basis. In relation to a necessary test for the existence of moral responsibility, John Martin Fischer and Mark Ravizza (Fischer, 1994; Fischer \& Ravizza, 1998) proposed a theory which determines a person as morally responsible for an action to the extent to which they can produce justifications determined by moral reasoning. Such theory presupposes the capacity to critically examine motivations and sources of actions, and thus the ability to recognise moral reasons for or against an action, together with the ability to translate these reasons and motivations into ethical actions. A person is receptive to moral reasoning in so far as they are able to consider doing something distinct from that which they feel inclined to do.

\section{The incapacity to distinguish between moral and social transgressions}

Finally, other studies restrict the concept of psychopathy to their incapacity to distinguish between moral and 
legal transgressions; they know that something is illegal but not that it is morally incorrect (Fine \& Kennett, 2004; Levy, 2007; Malatesti, 2010). The argument behind this authors' group is seen in an experiment carried out by Blair (1995) with ten imprisoned psychopaths and ten controls. The subjects evaluated four stories that contained moral transgressions and four others containing social transgressions. The moral transgressions were bad in themselves, independent of any legal or social sanctions, whereas the rest were dependent on authoritative sanctions. The hypothesis of this study was that the psychopaths would not be able to distinguish between moral and social transgressions, and would consider them all as if they were social ones. Nonetheless, the results were different from those hypothesized. In fact, the psychopaths considered all of the transgressions as moral ones. Subsequently, the experiment was replicated with a larger sample and they discovered that the psychopaths failed to make the distinction between moral and conventional social transgressions (Blair et al., 1995). Additionally, as compared to controls, psychopaths tend to explain their responses to moral transgressions in terms of harm to the wellbeing of others to a lesser degree. However, it is difficult to explain why psychopaths would consider all transgressions as moral ones, unless they were trying to mislead the interviewer in an attempt to earn penal privileges, or perhaps had exceptionally developed morality - something that is initially counterintuitive and contrary to construct. As an attempt to resolve this possible bias, Blair asked the psychopaths to respond in a way that they thought other individuals would when asked to classify these transgressions. The result was that the psychopaths correctly attributed the distinctions between moral and social transgressions. At least a "cognitive" ToM like that previously mentioned remains sufficiently intact due to the psychopaths' ability to attribute these differences to others (Aharoni et al., 2012, 2014).

\section{Difficulty in learning from their own experiences}

This argument highlights the difficulty psychopaths have in understanding the negative consequences of their actions as a result of the aforementioned difficulties in aversive and reverse learning. As a consequence of their impulsiveness and dissipative syndrome (Navas-Collado \& Muñoz-García, 2004), these subjects could find it difficult to learn from punishment and from an analysis of the consequences of their actions in the long run, which in turn could harm their moral development and their ethical capacity.

\section{Conclusions}

Psychopaths: "Mad or bad?" "Adaptive evolution from predatory man or moral incapacity?" As of today, there is a body of work backed by significant evidence highlighting the existence of structural, functional and neuropsychological abnormalities in patients with psychopathy. Nonetheless, it remains difficult to interpret these alterations in terms of moral and legal responsibility. As indicated by some authors, mistakes, errors and problems of interpretation are frequent (Jalava \& Griffiths, 2017), and there is an epistemological leap between the work of neuroscientists and their interpretation in terms of moral philosophy. The decisive question is not only about the existence of these neurobiological discoveries, but rather their correct interpretation. At this moment, there is no clear and defined neurobiological paradigm of moral responsibility which could be used to test and evaluate psychopaths in contrast to controls. Furthermore, the studies use diverse methods and are too varied, thus, in absence of such a paradigm, we cannot make direct assessments as to whether they reveal a deficit of moral responsibility directly measured. There is nothing close to a biological definition or a psychological operation for moral responsibility. Further, whilst it is possible to effectively define the biological and neuropsychological correlates of moral responsibility, such cannot be reduced to merely an experimentally verifiable and falsifiable question. Structural and functional brain alterations are not robust and consistent enough to ascertain that the neurobiological features required for moral reasoning in psychopaths are impaired. We do not know if these findings are simply correlates of their moral coldness. Furthermore, the probable impairment in emotions recognition, ToM and empathy do not impede, although it can limit, the moral activity. Emotions are a powerful avenue to understanding morality, but they are not the only one. Rationality is also another important pillar of moral reasoning, and it seems to be rather intact in psychopaths. Probable alterations in reversal learning or another deficit in executive functions seem not be definitive to exclude the moral responsibility. In fact, psychopaths can show a high level of performance in tasks requiring an adequate executive function. Moreover, psychopaths show a high level of violence, either reactive or instrumental (Blair et al., 2005), and this instrumental violence requires a sufficient cognitive and executive capability to be able to elaborate and execute plans, as well as plan distinct options.

In short, there is no definitive proof supporting the existence of a true biological determinism in terms of moral responsibility, although there is evidence that the latter is conditioned by biological and neuropsychological facts. As of today, psychopaths do not suffer from a mental disorder. Furthermore, they are not incapable of understanding the concepts of good and bad. Nor should their immorality be interpreted as an inability to understand social and juridical norms. 
Finally, in the absence of a clear and defined biological, neurobiological or neuropsychological paradigm corresponding to morality, the question as to the moral responsibility of psychopaths remains in the field of moral philosophy and is subject to evaluation and deliberation on a case by case basis.

\section{Abbreviations}

GWAS: Genome-wide association study; ToM: Theory of Mind

\section{Acknowledgements}

We thank Julia Daugherty, psychologist at the Mind and Brain Center in Granada (Spain), for her comments on the article and the review of the English language.

\section{Availability of data and materials}

Data sharing not applicable to this article as no datasets were generated or analysed during the current study.

\section{Authors' contributions}

This study was conceived and designed by JEMN and IIC. Analysis and interpretation of data was completed by JPMB, FS, BL and JPM. JEMN and JPMB drafted the manuscript. JPMB provided critical revision. All authors read and approved the final manuscript.

\section{Ethics approval and consent to participate}

Not applicable.

\section{Competing interests}

The authors declare that they have no competing interests.

\section{Publisher's Note}

Springer Nature remains neutral with regard to jurisdictional claims in published maps and institutional affiliations.

\section{Author details \\ 'Mental Health Clinical Management Unit Granada South, Andalusian Health Service, Granada, Spain. ${ }^{2}$ Andalusian Health Service, Granada, Spain. ${ }^{3}$ University of Edinburgh, Edinburgh, UK. ${ }^{4}$ University of Sofia, Sofia, Bulgaria. ${ }^{5}$ University of Granada, Granada, Spain. ${ }^{6}$ Psychiatric Unit of Baza Hospital, Andalusian Health Service, Granada, Spain. 'Departament of Personality, Assesssment and Psychological Treatment, University of Granada, Granada, Spain. ${ }^{8}$ Departament of Psychiatry, Faculty of Medicine, University of Granada, Avda. de la Investigación 11, 18016 Granada, Spain.}

Received: 30 December 2017 Accepted: 1 June 2018

Published online: 07 June 2018

\section{References}

Aharoni E, Sinnott-Armstrong W, Kiehl KA (2012) Can psychopathic offenders discern moral wrongs? A new look at the moral/conventional distinction. J Abnorm Psychol 121(2):484-497.

Aharoni E, Sinnott-Armstrong W, Kiehl KA (2014) What's wrong? Moral understanding in psychopathic offenders. J Res Pers 53:175-181 https://doi. org/10.1016/j.jp.2014.10.002.

Alcázar-Córcoles MA, Verdejo-García A, Bouso-Saiz JC (2008) La neuropsicología forense ante el reto de la relación entre cognición y emoción en la psicopatía. Rev Neurol 47(11):607-612.

American Psychiatric Association (2013) Diagnostic and statistical manual of mental disorders, 5th edn. American Psychiatric Publ, Washington, DC.

Bechara A, Damasio H, Damasio AR, Lee GP (1999) Different contributions of the human amygdala and ventromedial prefrontal cortex to decision-making. J Neurosci 19(13):5473-5481 http://www.jneurosci.org/content/19/13/5473.long.

Blair J, Mitchell D, \& Blair K (2005) The psychopath. Emotion and the brain. Malden: Blacwell Publishing.

Blair R (1995) A cognitive developmental approach to morality: investigating the psychopath. Cognition 57(1):1-29 https://doi.org/10.1016/00100277(95)00676-P.

Blair R (2003) Neurobiological basis of psychopathy. Br J Psychiatry 182(JAN.):5-7 https://doi.org/10.1192/bjp.182.1.5.
Blair R (2006) The emergence of psychopathy: implications for the neuropsychological approach to developmental disorders. Cognition 101(2): 414-442 https://doi.org/10.1016/j.cognition.2006.04.005.

Blair R (2007) The amygdala and ventromedial prefrontal cortex in morality and psychopathy. Trends Cogn Sci 11(9):387-392 https://doi.org/10.1016/j.tics. 2007.07.003.

Blair R (2008) The cognitive neuroscience of psychopathy and implications for judgments of responsibility. Neuroethics 1(3):149-157 https://doi.org/10. 1007/s12152-008-9016-6.

Blair R, Cipolotti L (2000) Impaired social response reversal a case of "acquired sociopathy.". Brain 123:1122-1141 https://doi.org/10.1093/brain/123.6.1122.

Blair R, Colledge E, Mitchell D (2001) Somatic markers and response reversal: is there orbitofrontal cortex dysfunction in boys with psychopathic tendencies? J Abnorm Child Psychol 29(6):499-511 https://doi.org/10.1023/A:1012277125119.

Blair R, Jones L, Clark F, \& Smith M (1995) Is the psychopath "morally insane? Personal Individ Differ, 19(5), 741-752.

Bloningen DM, Hicks BM, Krueger RF, Patrick CJ, lacono WG (2005) Psychopathic personality traits: heritability and genetic overlap with internalizing and externalizing psychopathology. Psychol Med 35(5):637-648 https://doi.org/10. 3816/CLM.2009.n.003.Novel.

Briken P, Habermann N, Berner W, Hill A (2006) XYY chromosome abnormality in sexual homicide perpetrators. Am J Med Genet 141 B(2):198-200 https://doi. org/10.1002/ajmg.b.30279.

Budhani S, Richell R a, Blair RJR (2006) Impaired reversal but intact acquisition: probabilistic response reversal deficits in adult individuals with psychopathy. J Abnorm Psychol 115(3):552-558 https://doi.org/10.1037/0021-843X.115.3.552.

Cleckley H (1994) The mask of sanity, 5th edn. Mosby, St Louis.

Coid J, Freestone M, Ullrich S (2012) Subtypes of psychopathy in the British household population: findings from the national household survey of psychiatric morbidity. Soc Psychiatry Psychiatr Epidemiol 47(6):879-891 https://doi.org/10.1007/s00127-011-0395-3.

Dadds, M. R., Perry, Y., Hawes, D. J., Merz, S., Riddell, A. C., Haines, D. J., .. Abeygunawardane, A. I. (2006). Attention to the eyes and fear-recognition deficits in child psychopathy. Br J Psychiatry, 189(SEP.), 280-281. https://doi org/10.1192/bjp.bp.105.018150.

Damasio, A. (1996). The Somatic Marker Hypothesis and the Possible Functions of the Prefrontal Cortex and Discussion_Damasio, Everitt, Bishop_Philosophical Transactions Biological Sciences_1996.pdf. Philos Trans R Soc Lond Ser B Biol Sci (Vol. 351). https://doi.org/10.1098/rstb.1996.0125.

Damasio A (2008) El error de Descartes $\left(5^{\circ}\right.$ ). Editorial Crítica, Barcelona.

Davis M, Whalen PJ (2001) The amygdala: vigilance and emotion. Mol Psychiatry 6(1):13-34 https://doi.org/10.1038/sj.mp.4000812.

Dawel A, O'Kearney R, McKone E, Palermo R (2012) Not just fear and sadness: meta-analytic evidence of pervasive emotion recognition deficits for facial and vocal expressions in psychopathy. Neurosci Biobehav Rev 36(10):22882304 https://doi.org/10.1016/j.neubiorev.2012.08.006.

Deigh J (1995) Empathy and universalizability. Ethics 105(4).

Dolan MC, Deakin JFW, Roberts N, Anderson IM (2002) Quantitative frontal and temporal structural MRI studies in personality-disordered offenders and control subjects. Psychiatry Res Neuroimaging 116(3):133-149 https://doi.org/ 10.1016/50925-4927(02)00085-9.

Dolan R, Fullam R (2004) Theory of mind and mentalizing ability in antisocial personality disorders with and without psychopathy. Psychol Med 34:10931102 https://doi.org/10.1017/50033291704002028.

Elliott C (1992) Diagnosing blame: responsibility and the psychopath. J Med Philos 17:199-214.

Everitt BJ, Cardinal RN, Parkinson JA, Robbins TW (2006) Appetitive behaviour. Ann N Y Acad Sci 985(1):233-250 https://doi.org/10.1111/j.1749-6632.2003. tb07085.x.

Fine C, Kennett J (2004) Mental impairment, moral understanding and criminal responsibility: psychopathy and the purposes of punishment. Int J Law Psychiatry 27(5):425-443 https://doi.org/10.1016/j.ijp.2004.06.005.

Finlay S (2011) The selves and the shoemaker: psychopaths, moral judgment, and responsibility. Southern J Philos 49(SUPPL. 1):125-133 https://doi.org/10. 1111/j.2041-6962.2011.00061.x.

Fischer JM (1994) The metaphysics of free will: an essay on control. Blackwell.

Fischer JM, Ravizza M (1998) Responsibility and control: a theory of moral responsibility. Cambridge University Press, Cambridge.

Flor H, Birbaumer N, Hermann C, Ziegler S, Patrick CJ (2002) Aversive Pavlovian conditioning in psychopaths: peripheral and central correlates. Psychophysiol 39(4):505-518 https://doi.org/10.1111/1469-8986.3940505. 
Frick PJ, Cornell AH, Barry CT, Bodin SD, Dane HE (2003) Callous-unemotional traits and conduct problems in the prediction of conduct problem severity, aggression, and self-report of delinquency. J Abnorm Child Psychol 31(4): 457-470 https://doi.org/10.1023/A:1023899703866.

Gazzaniga M (2006) El cerebro ético, 1st edn. Paidós Ibérica, Barcelona.

Gizer IR, Ehlers CL, Vieten C, Feiler HS, Gilder DA, Wilhelmsen KC (2012) Genomewide linkage scan of antisocial behavior, depression, and impulsive substance use in the UCSF family alcoholism study. Psychiatr Genet. 22(5): 235-44. https://doi.org/10.1097/YPG.0b013e328353fb77.

Glannon W (1997) Psychopathy and responsibility. J Appl Philos 14(3):263-275 https://doi.org/10.1111/1468-5930.00062.

Halty L, Martínez A, Santos JM, Ortiz T, Requena C (2011) Psicopatía en niños y adolescentes: modelos, teorías y últimas investigaciones. Rev Neurol 52(1):19-27 Retrieved from https://dialnet.unirioja.es/servlet/articulo? codigo $=4243382$.

Hare R (2003) Hare psychopathy checklist-revised manual, 2nd edn. Multi-Health Systems, Toronto.

Hare RD, Harpur TJ, Hakstian AR, Forth AE, Hart SD, Newman JP (1990) The revised psychopathy checklist: reliability and factor structure. Psychol Assess 2(3):338-341 https://doi.org/10.1037/1040-3590.2.3.338

Hariri A, Mattay V, Tessitore A, Kolachana B (2002) Serotonin transporter genetic variation and the response of the human amygdala. Science 297(July):400404 https://doi.org/10.1126/science.1071829.

Harpur T, Hakstian A, Hare R (1988) Factor structure of the psychopathy checklist. J Consult Clin Psychol 56(5):741-747.

Hart SD, \& Hare RD (1966) Psychopathy and antisocial personality disorder: current opinion in psychiatry. Current Opinion Psychiatry, 9(2), 129-132. Retrieved from https://journals.Iww.com/copsychiatry/Abstract/1996/03000/ Psychopathy_and_antisocial_personality_disorder.7.aspx.

Hauser M (2008) La mente moral, 1st edn. Paidós Ibérica, Barcelona.

Hiatt KD, Schmitt WA, Newman JP (2004) Stroop tasks reveal abnormal selective attention among psychopathic offenders. Neuropsychol 18(1):50-59 https:// doi.org/10.1037/0894-4105.18.1.50

Holmes CA (1991) Psychopathic disorder: a category mistake? J Med Ethics 17(2): 77-85 https://doi.org/10.1136/jme.17.2.77.

Jalava J, Griffiths S (2017) Philosophers on psychopaths: a cautionary tale in Interdisciplinarity. Philosophy Psychiatry Psychol 24(1):1-12.

Kiehl KA, Smith AM, Hare RD, Liddle PF (2000) An event-related potential investigation of response inhibition in schizophrenia and psychopathy. Bio Psychiatry 48(3):210-221 https://doi.org/10.1016/S0006-3223(00)00834-9.

Kiehl KA, Smith AM, Mendrek A, Forster BB, Hare RD, Liddle PF (2017) Temporal lobe abnormalities in semantic processing by criminal psychopaths as revealed by functional magnetic resonance imaging. Psychiatry Res Neuroimaging 130(1):27-42 https://doi.org/10.1016/S0925-4927(03)00106-9.

Levenston GK, Patrick CJ, Bradley MM, Lang PJ (2000) The psychopath as observer: emotion and attention in picture processing. J Abnorm Psychol 109(3):373-385 https://doi.org/10.1037/0021-843X.109.3.373.

Levy N (2007) The responsibility of the psychopath revisited. Philos Psychiatry Psychol 14(2):129-138. https://doi.org/10.1353/ppp.0.0003.

Levy N (2014) Psychopaths and blame: the argument from content. Philos Psychol 27(3):351-367 https://doi.org/10.1080/09515089.2012.729485.

Lynam DR, Caspi A, Moffitt TE, Loeber R, Stouthamer-Loeber M (2007) Longitudinal evidence that psychopathy scores in early adolescence predict adult psychopathy. J Abnorm Psychol 116(1):155-165. https://doi.org/10. 1037/0021-843X.116.1.155.

Maibom HL (2008) The mad, the bad, and the psychopath. Neuroethics 1(3):167184 https://doi.org/10.1007/s12152-008-9013-9.

Malatesti L (2010) Moral understanding in the psychopath. Synth Philos. Feb 24(2):337-348.

Navas-Collado E, Muñoz-García JJ (2004) El síndrome disejecutivo en la psicopatía. Rev Neurol 38(6):582-590.

Neumann CS, Hare RD, Pardini DA (2015) Antisociality and the construct of psychopathy: data from across the globe. J Pers 83(6):678-692 https://doi. org/10.1111/jopy.12127.

Patrick CJ, Cuthbert BN, Lang PJ (1994) Emotion in the criminal psychopath: fear image processing. J Abnorm Psychol 103(3):523-534 https://doi.org/10.1037/ 0021-843X.103.3.523.

Raine A, Ishikawa SS, Arce E, Lencz T, Knuth KH, Bihrle S et al (2004) Hippocampal structural asymmetry in unsuccessful psychopaths. Biol Psychiatry 55(2):185-191 https://doi.org/10.1016/S0006-3223(03)00727-3.

Raine A, Meloy JR, Bihrle S, Stoddard J, LaCasse L, Buchsbaum MS (1998) Reduced increased prefrontal subcortical and brain functioning assessed using positron emission tomography in predatory and affective murderers. Behav Sci Law 16:319-332.

Reniers RLEP, Corcoran R, Völlm BA, Mashru A, Howard R, Liddle PF (2012) Moral decision-making, ToM, empathy and the default mode network. Biol Psychol 90(3):202-210 https://doi.org/10.1016/j.biopsycho.2012.03.009.

Richell RA, Mitchell DGV, Newman C, Leonard A, Baron-Cohen S, Blair RJR (2003) Theory of mind and psychopathy: can psychopathic individuals read the "language of the eyes"? Neuropsychologia 41(5):523-526 https://doi.org/10. 1016/S0028-3932(02)00175-6.

Rilling JK, Glenn AL, Jairam MR, Pagnoni G, Goldsmith DR, Elfenbein HA, Lilienfeld SO (2007) Neural correlates of social cooperation and non-cooperation as a function of psychopathy. Biol Psychiatry 61(11):1260-1271 https://doi.org/10. 1016/j.biopsych.2006.07.021.

Rutter M (2005) Commentary: what is the meaning and utility of the psychopathy concept? J Abnorm Child Psychol 33(4):499-503 https://doi.org/ 10.1007/s10802-005-5730-2.

Schmitt W, Brinkley C, Newman JP (1999) Testing Damasio's somatic marker hypothesis with psychopathic individuals: risk takers or risk averse? J Abnorm Psychol 108(3):538-543. https://doi.org/10.1037/0021-843X.108.3.538.

Shamay-Tsoory SG, Harari H, Aharon-Peretz J, Levkovitz Y (2010) The role of the orbitofrontal cortex in affective theory of mind deficits in criminal offenders with psychopathic tendencies. Cortex 46(5):668-677 https://doi.org/10.1016/j. cortex.2009.04.008.

Silverthorn P, Frick PJ (1999) Developmental pathways to antisocial behavior: the delayed-onset pathway in girls. Dev Psychopathol 11(1):101-126 https://doi. org/10.1017/S0954579499001972.

Torrubia-Beltri R, Cuquerella-Fuentes Á (2008) Psicopatía: Una entidad clínica controvertida pero necesaria en psiquiatría forense. Revista Espanola de Medicina Legal 34(1):25-35 https://doi.org/10.1016/S0377-4732(08)70023-3.

Viding E, Blair RJR, Moffitt TE, Plomin R (2005) Evidence for substantial genetic risk for psychopathy in 7-years-olds. J Child Psychol Psychiatry 46(6):592-597 https://doi.org/10.1111/j.1469-7610.2004.00393.x.

Vierra A (2016) Psychopathy, mental time travel, and legal responsibility. Neuroethics 9(2):129-136 https://doi.org/10.1007/s12152-015-9243-6.

World Health Organization (1992) The ICD-10 classification of mental and behavioural disorders: clinical descriptions and diagnostic guidelines. World Health Organization, Geneva.

Yang Y, Raine A (2008) Functional neuroanatomy of psychopathy. Psychiatry 7(3): 133-136 https://doi.org/10.1016/j.mppsy.2008.01.001.

Yang Y, Raine A, Lencz T, Bihrle S, LaCasse L, Colletti P (2005) Volume reduction in prefrontal grey matter in unsuccessful criminal psychopaths. Biol Psychiatry 57(10):1103-1108 https://doi.org/10.1016/j.biopsych.2005.01.021.

Yang Y, Raine A, Narr K, Colletti P, Toga A (2009) Localization of deformations within the amygdala in individuals with psychopathy. Arch Gen Psychiatry 66(9):986-994.

\section{Submit your manuscript to a SpringerOpen ${ }^{\mathcal{O}}$ journal and benefit from:}

- Convenient online submission

- Rigorous peer review

- Open access: articles freely available online

- High visibility within the field

Retaining the copyright to your article

Submit your next manuscript at $>$ springeropen.com 